\title{
BMJ Open Maternal and fetal characteristics and causes of stillbirth in a tertiary care hospital of Nepal: secondary analysis of registry-based surveillance data
}

\author{
Basant Sharma (D) , ${ }^{1}$ Suraj Bhattarai (D) , ${ }^{2}$ Sabita Shrestha, ${ }^{1}$ Rakshya Joshi, \\ Renuka Tamrakar, ${ }^{1}$ Prekshya Singh, ${ }^{1}$ Jully Chaudhary, ${ }^{1}$ Upendra Pandit ${ }^{1}$
}

To cite: Sharma B, Bhattarai S, Shrestha S, et al. Maternal and fetal characteristics and causes of stillbirth in a tertiary care hospital of Nepal: secondary analysis of registry-based surveillance data. BMJ Open 2021;11:e045012. doi:10.1136/ bmjopen-2020-045012

- Prepublication history for this paper is available online. To view these files, please visit the journal online (http://dx.doi. org/10.1136/bmjopen-2020045012).

Received 22 September 2020 Accepted 31 July 2021

Check for updates

(c) Author(s) (or their employer(s)) 2021. Re-use permitted under CC BY-NC. No commercial re-use. See rights and permissions. Published by BMJ.

${ }^{1}$ Obstetrics and Gynecology, Chitwan Medical College, Bharatpur, Chitwan, Nepal ${ }^{2}$ Global Health, Global Institute for Interdisciplinary Studies, Kathmandu, Nepal

Correspondence to

Dr Suraj Bhattarai;

suraj@thegiis.org

\section{ABSTRACT}

Objectives Stillbirth is one of the vital indicators of quality care. This study aimed to determine maternal-fetal characteristics and causes of stillbirth in Nepal.

Design Secondary analysis of single-centred registrybased surveillance data.

Setting The study was conducted at the Department of Obstetrics and Gynecology, Chitwan Medical College Teaching Hospital, a tertiary care hospital located in Bharatpur, Nepal.

Participants All deliveries of intrauterine fetal death, at or beyond 22 weeks' period of gestation and/or birth weight of $500 \mathrm{~g}$ or more, conducted between 16 July 2017 and 15 July 2019 were included in the study.

Main outcome measures The primary outcome measure of this study was stillbirth, and the secondary outcome measures were maternal and fetal characteristics and cause of stillbirth.

Results Out of 5282 institutional deliveries conducted over 2 years, 79 (1.5\%) were stillbirths, which gives the stillbirth rate of 15 per 1000 births. Of them, the majority (75; $94.9 \%)$ were vaginal delivery and only four $(5.1 \%)$ were caesarean section $(p<0.0001)$. The proportion of the macerated type of stillbirth was more than that of the fresh type ( $58.2 \%$ vs $41.8 \% ; p=0.13)$. Only half of the mothers who experienced stillbirth had received antenatal care. While the cause of fetal death was unknown in one-third of cases $(31.6 \% ; 25 / 79)$, among likely causes, the most common was maternal hypertension (29.1\%), followed by intrauterine infection (8.9\%) and fetal malpresentation (7.6\%). Four out of 79 stillbirths (5\%) had a birth defect. Conclusion High rate of stillbirths in Nepal could be due to the lack of quality antenatal care. The country's health systems should be strengthened so that pregnancy-related risks such as maternal hypertension and infections are identified early on. Upgrading mothers' hygiene and health awareness is equally crucial in reducing fetal deaths in low-resource settings.

\section{INTRODUCTION}

Stillbirth is a tragic event to the mother, family and healthcare providers. ${ }^{1}$ It is a vital indicator of health and development of a country. According to the WHO, stillbirth is defined as a baby delivered without signs of life at or
Strengths and limitations of this study

- The study analysed the rich data collected by globally accepted Maternal and Perinatal Death Surveillance and Response programme.

- The likely cause of stillbirth was determined by clinical assessment of the mother and the fetus, but autopsy findings would have given the most accurate cause of fetal death.

- The facility-based registry excludes fetal deaths or stillbirths that occur at household or community level, so the surveillance area and criteria need to be revised.

after 28 weeks of gestation. ${ }^{2}$ This definition of stillbirth corresponds to the International Classification of Diseases (ICD) ascertainment of late fetal death (birth weight $1000 \mathrm{~g}$ or $\geq 28$ weeks or $\geq 35 \mathrm{~cm}$ ). ${ }^{34}$

Over 2.6 million stillbirths occur annually worldwide, $98 \%$ of them occurring in low and middle-income countries (LMICs). ${ }^{2}{ }^{5}$ The rate of stillbirth also varies in different countries, ranging from 5 per 1000 births in high-income countries to 36 per 1000 births in developing countries. ${ }^{5}$ It was 18.4 per 1000 births worldwide in $2015 .^{2}$ In Nepal, the 5-year (2011-2016) perinatal mortality and extended perinatal mortality rates were 42 and 49 per 1000 births, respectively, and stillbirth rate was estimated to be 33.4 per 1000 births. ${ }^{67}$

There are various factors associated with stillbirths, such as maternal diabetes, hypertensive disorders, intrauterine sepsis and fetal growth restriction. ${ }^{8}$ Since distribution of fetal deaths correlates with that of maternal deaths (majority of them occurring in South Asia and sub-Saharan Africa, mostly in rural areas), unavailability of high-skilled healthcare professionals in these areas could also be a likely reason for high stillbirth rates. The 
WHO estimates show that half of the stillbirths worldwide (1.3 million) occur during labour and birth, mostly due to preventable conditions. ${ }^{2} \mathrm{~A}$ fresh type of stillbirth means intrauterine death of fetus during labour or delivery (could have preceded by 24 hours or so), whereas a macerated type suggests intrauterine fetal death sometime before the onset of labour with the fetus undergoing degenerative changes. ${ }^{10}$

Timely identification of pregnancy-related risk factors by clinicians can reduce the incidence of fetal deaths. Likewise, determination of the cause of fetal death through surveillance programmes such as Maternal and Perinatal Death Surveillance and Response (MPDSR), minimally invasive tissue sampling, can inform the governments and stakeholders of their public health priorities to reach the national target of less than 10 stillbirths per 1000 births by $2035 .{ }^{11-13}$ However, both of these approaches might be difficult to fully implement in lowresource settings. World leaders recommend that health institutions with the mandate to provide maternal and child health services should take leadership by promoting healthy and safe pregnancies. ${ }^{14}$ There is a lack of uniform data on stillbirth in Nepal. This study aims to analyse the registry-based data to determine the burden, maternalfetal characteristics and causes of stillbirth in Nepal, the findings of which will help clinicians, health institutions and health system actors plan and implement the preventive programmes.

\section{METHODS}

This is a secondary analysis of registry-based surveillance data collected at the Department of Obstetrics and Gynecology (OBGYN), Chitwan Medical College Teaching Hospital (CMCTH), Bharatpur, from 16 July 2017 to 15 July 2019. The registry of maternal and perinatal deaths is maintained by CMCTH and coordinated by the Family Welfare Division at the Ministry of Health and Population. ${ }^{15}$ CMCTH is a 750-bed non-government hospital that serves a catchment area of nearly 1 million population living across seven municipalities of Chitwan district in Bagmati Province and 11 municipalities of Gorkha district in Gandaki Province. The OBGYN department has a total of 120 beds, with most beds occupied by maternity cases. ${ }^{16}$ The department provides obstetric care to over 2500 mothers annually. Although there is another tertiary-level non-government teaching hospital (College of Medical Sciences) and a government district hospital in the periphery, CMCTH is the major hub for obstetric care.

Our definition of stillbirth corresponds to ICD ascertainment of early ( $\geq 500 \mathrm{~g}$ or $\geq 22$ weeks or $\geq 25 \mathrm{~cm}$ ) and late $(\geq 1000 \mathrm{~g}$ or $\geq 28$ weeks or $\geq 35 \mathrm{~cm})$ fetal deaths. ${ }^{34}$ Hence, deliveries of all fetal deaths in uterus at or beyond 22 weeks of gestation (determined by ultrasonography) and/or birth weight of $500 \mathrm{~g}$ or more were included in the analysis. Fetal death was confirmed by the absence of fetal heart sounds and an ultrasonography performed during admission as well as during labour monitoring. Mother's age, obstetric index and pregnancy-related risk factors such as pre-eclampsia, gestational diabetes mellitus, oligohydramnios, polyhydramnios and $\mathrm{Rh}$ negativity were recorded. Information on the mode of delivery, baby details (weight, gross congenital anomalies), colour and amount of liquor, type of stillbirth (macerated or fresh) and gross placental morphology were also recorded.

The clinicians at the department of OBGYN have been trained to register stillbirth case, as per the guidelines of MPDSR programme. The data collected by the programme are monitored by the technical officers at the Family Welfare Division, Ministry of Health and Population as well as those recruited by supporting partners such as WHO and UNICEF. The likely cause of death is determined by the panel of clinicians designated by MPDSR programme, based on the clinical and radiological assessments of the mother and the fetus.

Data were analysed using the statistical software package SPSS V.20.0. Descriptive statistics was used to estimate the mean, $\mathrm{SD}$ and association between variables. $\mathrm{P}$ value $<0.05$ was considered statistically significant.

\section{Patient and public involvement}

It was not appropriate or possible to involve the patients or the public in the study design, or conduct, or reporting, or dissemination plans of our research. However, the study team has considered inviting them to discussion sessions in the future.

\section{RESULTS}

Out of 5282 deliveries conducted at the study centre during a 2-year study period, 79 stillbirths were reported, with stillbirth rate of 15 per 1000 births. Age of women who experienced stillbirth ranged from 15 to 40 years with a mean age of $24.6(\mathrm{SD} \pm 5.2)$. Majority $(64.6 \%)$ were illiterate (no formal education), and by religion were Hindu (69.6\%) and Buddhist (17.7\%) (table 1). The proportion of stillbirth was found high in women who were $21-30$ years of age $(67.1 \%)$, illiterate $(64.6 \%)$ and Hindu by religion $(69.6 \%)$.

Of 79 deliveries that resulted in stillbirth, $75(94.9 \%)$ were vaginal deliveries; $45(57 \%)$ were male and $34(43 \%)$ were female. Macerated type of stillbirth $(58.2 \%)$ was more common than fresh type $(41.8 \%)$. Half $(48.1 \%)$ of the mothers who experienced stillbirth were primigravida. Likewise, only half $(49.4 \%)$ reported receiving antenatal care (ANC) (at least one ANC visit) (table 2). The mean gestational age was 32 weeks $( \pm 5.7)$, with the majority $(50 / 79 ; 63.3 \%)$ of fetal deaths occurring preterm. The same percentage of fetuses had a weight below $3000 \mathrm{~g}$, although it ranged from 422 to $4050 \mathrm{~g}$ (table 2). There was a significant association between fetal death and mode of delivery, gestational age and weight of the fetus.

Out of 79 stillbirths, 25 (31.6\%) had an unknown cause of death. Of those with known cause, the most common was maternal hypertensive disorder $(23 ; 29.1 \%)$ followed 


\begin{tabular}{|c|c|}
\hline Characteristics & Frequency of stillbirth (\%) \\
\hline \multicolumn{2}{|l|}{ Age (years) } \\
\hline $11-20$ & $16(20.3)$ \\
\hline $21-30$ & $53(67.1)$ \\
\hline $31-40$ & $10(12.7)$ \\
\hline \multicolumn{2}{|c|}{$\begin{array}{l}\text { Mean } \pm S D=24.6 \pm 5.2 \\
\text { Range } 15-40\end{array}$} \\
\hline \multicolumn{2}{|l|}{ Education level } \\
\hline Literate & $28(35.4)$ \\
\hline Illiterate & $51(64.6)$ \\
\hline \multicolumn{2}{|l|}{ Religion } \\
\hline Hindu & 55 (69.6) \\
\hline Buddhist & $14(17.7)$ \\
\hline Christian & $6(7.6)$ \\
\hline Muslim & $4(5.1)$ \\
\hline
\end{tabular}

by intrauterine infection $(7 ; 8.9 \%)$, fetal malpresentation $(6 ; 7.6 \%)$, cord accident $(4 ; 5.1 \%)$ and maternal endocrine disorders $(4 ; 5.1 \%)$. Stillbirth rate was as high as 4 per 1000 births (23 of 5282 deliveries) in hypertensive mothers. Four babies were born with congenital defects: one anencephaly, one hydrops fetalis, one omphalocele and one spina bifida (table 3).

\section{DISCUSSION}

The stillbirth rate in our centre was 15 per 1000 births, which is comparable to the estimates for South Asian countries, but lower than that reported in the majority of LMICs worldwide. ${ }^{3717}$ The cause of fetal death was unknown in $31.6 \%$ of cases in our centre; it was as high as $52 \%$ in Bangladesh. ${ }^{18}$ A recent review of globally reported stillbirths, nearly half of million cases from 50 countries, also revealed that the majority were unexplained. ${ }^{19}$

Antepartum fetal death contributes to perinatal mortality rate. It was found that $90 \%$ of mothers who experienced stillbirths were not booked for ANC service. A study conducted in another health centre of Nepal reported a similar finding (91\% not booked), but booking trend varied in other countries: $85.1 \%$ in Pakistan, $55 \%-57.5 \%$ in Nigeria. ${ }^{20-23}$ Of all stillbirths, the highest proportion occurred in 21-30year-olds, and among illiterate women. From the developing world's perspectives, strengthening institutional capacities and upgrading women's education and health awareness level could help in promoting healthy and safe pregnancies. ${ }^{14}$

Fetal death can occur without a known cause. Likely cause of death was unknown in approximately one-third of stillbirths in the current study and in other studies in Nepal and Nigeria. ${ }^{20} 2425$ Among the identified cause of fetal death, pregnancy-related hypertension was the most common followed by intrauterine infections. Intrauterine
Table 2 Maternal and fetal characteristics of stillbirth $(n=79)$

\begin{tabular}{|c|c|c|}
\hline Characteristics & $\begin{array}{l}\text { Frequency } \\
\text { of stillbirth } \\
(\%)\end{array}$ & $\mathrm{X}^{2} \mathrm{P}$ value \\
\hline Mode of delivery & & $<0.0001$ \\
\hline Vaginal & $75(94.9)$ & \\
\hline Caesarean & $4(5.1)$ & \\
\hline Type of stillbirth & & 0.13 \\
\hline Fresh & $33(41.8)$ & \\
\hline Macerated & $46(58.2)$ & \\
\hline Sex of fetus & & 0.21 \\
\hline Male & $45(57.0)$ & \\
\hline Female & $34(43.0)$ & \\
\hline Antenatal care & & 0.12 \\
\hline ANC received & $39(49.4)$ & \\
\hline ANC not received & $40(50.6)$ & \\
\hline History of pregnancy & & 0.73 \\
\hline Primigravida & $38(48.1)$ & \\
\hline Multigravida & $41(51.9)$ & \\
\hline Gestational age (weeks) & & 0.0238 \\
\hline$\leq 25$ & $11(13.9)$ & \\
\hline $26-30$ & $23(29.1)$ & \\
\hline $31-35$ & $16(20.3)$ & \\
\hline 36 and above & $29(36.7)$ & \\
\hline \multicolumn{3}{|l|}{$\begin{array}{l}\text { Mean } \pm S D=32.0 \pm 5.7 \\
\text { Range } 22-41\end{array}$} \\
\hline Weight of fetus (g) & & 0.0238 \\
\hline$<1000$ & $11(13.9)$ & \\
\hline 1000-1999 & $23(29.1)$ & \\
\hline 2000-2999 & $16(20.3)$ & \\
\hline 3000 and above & $29(36.7)$ & \\
\hline $\begin{array}{l}\text { Mean } \pm S D=1794 \pm 1015.8 \\
\text { Range } 422-4050\end{array}$ & & \\
\hline
\end{tabular}

ANC, antenatal care.

\begin{tabular}{|c|c|}
\hline Likely cause of stillbirth & Frequency (\%) \\
\hline Hypertensive disorder & $23(29.1)$ \\
\hline Intrauterine infection & 7 (8.9) \\
\hline Endocrine disorder & $4(5.1)$ \\
\hline Cord accident & $4(5.1)$ \\
\hline Oligohydramnios & $4(5.1)$ \\
\hline Postdated pregnancy & $2(2.5)$ \\
\hline Fetal growth restriction & $2(2.5)$ \\
\hline Fetal malpresentation & $6(7.6)$ \\
\hline Birth defects & $4(5.1)$ \\
\hline Unknown cause & $25(31.6)$ \\
\hline
\end{tabular}


infections are usually caused by sexually transmitted pathogens, but they may also be due to other pathogens like group B Streptococcus (GBS).$^{26}$ Studies conducted in India and Pakistan found severe anaemia and abnormal labour as the most common causes of fetal death, respectively. ${ }^{24}$ Our findings suggest that cause-specific prevention strategies might be needed to reduce the risk of stillbirth, for example, regular screening of high blood pressure, improving personal and sexual hygiene, use of barriers to prevent sexually transmitted infections, GBS screening and effective vaccines. ${ }^{26} 27$

The proportion of macerated stillbirth was found higher than that of fresh type, indicating many fetuses tend to die without mothers reaching hospital for delivery. This finding highlights the importance of raising maternal awareness about danger signs associated with intrauterine fetal complications or demise. In our study, four fetal death cases $(5 \%)$ had to be delivered by caesarean section, reasons being placenta previa, malpresentation and previous caesarean with scar tenderness. Other studies reported $11.48 \%-13.8 \%$ of fetal deaths requiring operational delivery. ${ }^{20}{ }^{24}$ Placental abnormalities have been reported to be associated with stillbirth. $^{28}$

Preterm fetal death was found high in this study, so was the proportion of death among low-weight fetuses $(63.3 \%$ each). Preterm death rate varied from $36 \%$ to $54 \%$ in other studies. ${ }^{7202429}$ According to the studies conducted in high-income countries, there is an increased risk of stillbirth (as high as $64 \%$ ) with advancing gestation in term pregnancies. ${ }^{30}$ Half of the fetal deaths in our study were attributed to primigravida mothers, comparable to other studies in Nepal. ${ }^{2031}$ Moreover, studies have reported that women who experienced stillbirth in their first pregnancy are five times more likely to experience stillbirth in their second pregnancy, compared with women who had a live birth in their first pregnancy. ${ }^{32}$

Congenital malformations in the fetus are also considered a risk factor for stillbirth. Four (5\%) of 79 fetal deaths had a congenital defect in our study, which is in line with other studies, but less than that reported in India. ${ }^{24} 2931$

The study has some limitations. First, the cause of fetal death was determined on the basis of the patient's clinical and radiological assessment. Autopsy of the dead fetus and histopathology examination of the placenta could have revealed the exact cause of death. Those procedures were not performed because of sociocultural barriers. Second, this is an analysis of facility-based registry data that exclude fetal deaths occurring at household or community level, without mother being brought to the hospital. Third, this is a single-centre study, so the findings may not be representative of the overall population of Nepal. Fourth, a relatively small number of stillbirths (79 out of 5282) may affect the precision and significance of statistical estimates given in result tables.

\section{CONCLUSIONS}

The cause of death was unknown in one-third of stillbirths, and among those with likely causes, maternal hypertension was the most common followed by intrauterine infection, both of which are preventable if ANC is improved. Health systems strengthening is essential to identify pregnancy-related risks early on during maternal journey and prevent fetal deaths in low-resource settings. From mothers' perspectives, improving their hygiene habits and health awareness could render favourable fetal outcomes.

\section{Twitter Suraj Bhattarai @BhattaraiS and Upendra Pandit @Ū}

Acknowledgements We thank the hospital administration and the Department of Obstetrics and Gynecology at CMCTH for allowing us to extract the registrybased data. We thank all the clinicians and assistants who were involved in the management of stillbirths. We also thank the anonymous reviewers for their comments and feedback to the older versions of the manuscript.

Contributors BS and UP were responsible for the concept and design of the study. $\mathrm{BS}, \mathrm{SS}, \mathrm{RJ}, \mathrm{RT}, \mathrm{PS}$ and JC were directly involved in clinical management of stillbirth cases. BS and SB analysed the data and wrote the first draft of the manuscript. All authors reviewed and agreed on the submitted version of the manuscript.

Funding The authors have not declared a specific grant for this research from any funding agency in the public, commercial or not-for-profit sectors.

Competing interests None declared.

Patient and public involvement Patients and/or the public were not involved in the design, or conduct, or reporting, or dissemination plans of this research.

Patient consent for publication Not required.

Ethics approval This study was approved by the Institutional Ethical Review Board of Chitwan Medical College (Ref: CMC-IRC/076/077-109). Since this is a secondary data analysis, written informed consent from the patients was waived by the review board.

Provenance and peer review Not commissioned; externally peer reviewed.

Data availability statement Data are available upon reasonable request. All data relevant to the study are included in the article or uploaded as supplementary information. Patients' deidentified data are available from the lead author (subject to institutional approval) upon a reasonable request.

Open access This is an open access article distributed in accordance with the Creative Commons Attribution Non Commercial (CC BY-NC 4.0) license, which permits others to distribute, remix, adapt, build upon this work non-commercially, and license their derivative works on different terms, provided the original work is properly cited, appropriate credit is given, any changes made indicated, and the use is non-commercial. See: http://creativecommons.org/licenses/by-nc/4.0/.

ORCID iDs

Basant Sharma http://orcid.org/0000-0002-8317-5388

Suraj Bhattarai http://orcid.org/0000-0001-6843-6677

\section{REFERENCES}

1 World Health Organization. Making every baby count: audit and review of stillbirths and neonatal deaths, 2016. Available: https:// www.who.int/publications/i/item/9789241511223

2 World Health Organization. Stillbirths, 2020. Available: https://www. who.int/maternal_child_adolescent/epidemiology/stillbirth/en/

3 Lawn JE, Blencowe H, Pattinson R, et al. Stillbirths: where? When? Why? How to make the data count? The Lancet 2011;377:1448-63.

4 Tavares Da Silva F, Gonik B, McMillan M, et al. Stillbirth: case definition and guidelines for data collection, analysis, and presentation of maternal immunization safety data. Vaccine 2016;34:6057-68.

5 Cousens S, Blencowe H, Stanton C, et al. National, regional, and worldwide estimates of stillbirth rates in 2009 with trends since 1995: a systematic analysis. Lancet 2011;377:1319-30.

6 Ghimire PR, Agho KE, Renzaho AMN, et al. Factors associated with perinatal mortality in Nepal: evidence from Nepal demographic and health survey 2001-2016. BMC Pregnancy Childbirth 2019;19:88. 
7 Aminu M, Unkels R, Mdegela M, et al. Causes of and factors associated with stillbirth in low- and middle-income countries: a systematic literature review. BJOG 2014;121 Suppl 4:141-53.

8 Gardosi J, Madurasinghe V, Williams M, et al. Maternal and fetal risk factors for stillbirth: population based study. BMJ 2013;346:f108.

9 Fretts RC. Etiology and prevention of stillbirth. Am J Obstet Gynecol 2005:193:1923-35.

10 Feresu SA, Harlow SD, Welch K, et al. Incidence of stillbirth and perinatal mortality and their associated factors among women delivering at Harare maternity Hospital, Zimbabwe: a cross-sectional retrospective analysis. BMC Pregnancy Childbirth 2005;5:9.

11 World Health Organization. Maternal death surveillance and response (MDSR); 2020.

12 Madhi SA, Pathirana J, Baillie V, et al. An observational pilot study evaluating the utility of minimally invasive tissue sampling to determine the cause of stillbirths in South African women. Clin Infect Dis 2019;69:S342-50.

13 Lawn JE, Blencowe H, Oza S, et al. Every newborn: progress, priorities, and potential beyond survival. Lancet 2014;384:189-205.

14 Frøen JF, Friberg IK, Lawn JE, et al. Stillbirths: progress and unfinished business. Lancet 2016;387:574-86.

15 Family Health Division Ministry of Health. Country update Nepalbuilding on MPDRs to implement MPDSR, 2016. Available: http:// mdsr-action.net/updates/nepal-building-on-mpdrs-to-implementmpdsr/

16 Government of Nepal Ministry of Health and Population. DoHS annual report FY 2075-76, 2020. Available: http://dohs.gov.np/dohsannual-report-fy-2076-77/

17 Jindal A, Thakur R, Minhas S. Causes of stillbirth according to different gestational ages. Int J Reprod Contraception, Obstet Gynecol 2018.

18 Halim A, Aminu M, Dewez JE, et al. Stillbirth surveillance and review in rural districts in Bangladesh. BMC Pregnancy Childbirth 2018;18:224.

19 Reinebrant HE, Leisher SH, Coory M, et al. Making stillbirths visible: a systematic review of globally reported causes of stillbirth. BJOG 2018:125:212-24.
20 Thakur A, Basnet $\mathrm{P}$, Rai R, et al. Risk factors related to intrauterine fetal death. J Nepal Health Res Counc 2019;17:46-50.

21 Kuti O, Owolabi AT, Orji EO, et al. Antepartum fetal death in a Nigerian teaching hospital: aetiology and risk factors. Trop J Obstet Gynaecol 2004;20.

22 Audu. Risk factors for stillbirths at universty of Maiduguri teaching Hospital, Maiduguri, Nigeria: a cross-sectional retrospective analysis. Nigerian Medical Journal 2009.

23 Rehan N. Still births in a Hausa community. J Pak Med Assoc 1982.

24 Singh N, Pandey K, Gupta N, et al. A retrospective study of 296 cases of intra uterine fetal deaths at a tertiary care centre. Int $J$ Reprod Contracept Obstet Gynecol 2013:141-6.

25 Shaaban LA, Al-Saleh RA, Alwafi BM, et al. Associated risk factors with ante-partum intra-uterine fetal death. Saudi Med J 2006;27:76-9.

26 Seale A, Bianchi-Jassir F, Russell N. G292(P) Estimates of the burden of group $b$ streptococcal disease worldwide for pregnant women, stillbirths and children. Archives of Disease in Childhood 2018;103:A119-20.

27 Bevan D, White A, Marshall J, et al. Modelling the effect of the introduction of antenatal screening for group B Streptococcus (GBS) carriage in the UK. BMJ Open 2019;9:e024324.

28 Bukowski R, Hansen NI, Pinar H, et al. Altered fetal growth, placental abnormalities, and stillbirth. PLoS One 2017;12:e0182874

29 Jehan I, McClure EM, Salat S, et al. Stillbirths in an urban community in Pakistan. Am J Obstet Gynecol 2007;197:257.e1-257. e8.

30 Muglu J, Rather H, Arroyo-Manzano D, et al. Risks of stillbirth and neonatal death with advancing gestation at term: a systematic review and meta-analysis of cohort studies of 15 million pregnancies. PLOS Med 2019;16:e1002838.

31 Tamrakar SR, Chawla CD. Intrauterine foetal death and its probable causes: two years experience in Dhulikhel Hospital-Kathmandu university hospital. Kathmandu Univ Med J 2012;10:44-8.

32 Lamont K, Scott NW, Jones GT, et al. Risk of recurrent stillbirth: systematic review and meta-analysis. BMJ 2015;350:h3080. 